\title{
Comparison among different software for photovoltaic plants projects: Case study
}

\section{Fernando Valente de Menezes Júnior ${ }^{1}$, Jorge Laureano Moya Rodriguez ${ }^{2}$}

\author{
${ }^{1,}$ Universidade Federal do Pará. Rua Augusto Corrêa, 01 - Guamá. CEP 66075-110 - Belém Pará - Brasil.PA. \\ ${ }^{2,}$ Universidade Federal da Bahia - Ondina, CEP: 40170-115 - Salvador - BA,
}

Email: fernandovalente@live.com,jorgemoyar@gmail.com

Received: October $27^{\text {th }}, 2017$.

Accepted: November 29th, 2017

Published: December $30^{\text {th }}, 2017$

Copyright (2016 by authors and Institute of Technology Galileo of Amazon (ITEGAM).This work is licensed under the Creative Commons Attribution International License (CC BY 4.0). http://creativecommons.org/licenses/by/4.0/

\section{ABSTRACT}

Due to a need to search for new and diverse energetic alternatives, a photovoltaic energy is distinguished by the amount of energy received on our planet in a clean way, through the solar rays, which in addition to bringing light and heat to a life on Earth, can be approved for a generation of electricity. The study focuses on the municipality of Itacoatiara-AM, where it is part of the author's work history, and software for evaluating photovoltaic plant projects in the chosen location is compared. These presented results, besides specific information of each, returning values acceptable for future projection, demonstrated in the work. The software PVSyst, RETScreen and System Advisor Model were chosen to carry out the comparison of the results. PVSyst has a wide scope in the design and performance of systems, since RETScreen analyzes more deeply the financial resources, balances and risks during the installation project in front of the demands of sustainability and with the SAM, it is possible to identify more easily projects that are analyzed by performance and financial analysis, facilitating decision-making. As methodologies, they presented minimum variations between them in relation as measures of irradiation and effectiveness that present in the region under study with little variation of the respective software. Thus, the potential of the generation has proved to be very promising and a great part of this is due to the high solar radiation indices not in Brazil and mainly in the North region and the new technologies of the generation modules.

Keywords: solar energy- economic aspects, generation of photovoltaic energy- projects, energyalternative sources, software's.

\section{Comparação entre os diferentes softwares para projetos de plantas fotovoltaicas: Estudo de caso}

\section{RESUMO}

Por uma necessidade da busca de novas e diversas alternativas energéticas, a energia fotovoltaica destaca-se pela quantidade de energia recebida em nosso planeta de forma limpa, através dos raios solares, que além de trazerem a luz e calor para a vida na Terra, podem ser aproveitados para a geração de eletricidade. O estudo foca no município de Itacoatiara-AM, onde faz parte da história do autor deste trabalho e são comparados softwares para avaliação de projeção de plantas fotovoltaicas na localidade escolhida. Estes apresentaram resultados semelhantes, contendo informações específicas de cada, retornando valores aceitáveis para projeção futuras, demonstrados no trabalho. Os softwares PVSyst, RETScreen e System Advisor Model, foram escolhidos para execução da comparação dos resultados. O PVSyst possui abrangência no dimensionamento e desempenho dos sistemas, já RETScreen analisa mais profundamente o desempenho financeiros, payback e riscos durante o projeto de instalação diante das demandas de sustentabilidade e com o SAM, é possível identificar com mais facilidade projetos que serão analisados por desempenho e análise financeira, facilitando a tomada de decisões. As metodologias apresentaram variações mínimas entres eles e em relação as medidas de irradiação e efetividade que apresenta na região em estudo com pouca variação dos respectivos softwares. De modo que o potencial da geração demonstrou-se bastante promissor e grande parte disto, deve-se ao fato dos altos índices de radiação solar no Brasil e principalmente da região Norte e das novas tecnologias dos módulos da geração.

Palavras-chave: energia solar- aspectos econômicos, geração de energia fotovoltaica- projetos, energia- fontes alternativas,softwares. 


\section{INTRODUÇÃO}

Dentre as chamadas fontes alternativas ou renováveis de energia, a energia solar destaca-se devido a sua abundância, podendo ser utilizada como fonte de calor (solar térmica) ou de energia elétrica (solar fotovoltaica) [1]. Na energia solar fotovoltaica, há conversão direta da radiação solar em energia elétrica. Tal conversão de energia é realizada através da célula solar fotovoltaica, que é passível de utilização em locais remotos [2],[3]. Da geração poluente da maioria das formas de transformações da energia mecânica em energia elétrica existentes, surgem como proposta tecnológica, fontes de energias alternativas descentralizadas, aproveitando alguns tipos de energia "limpa" gerada por recursos renováveis.

Nos últimos anos o Brasil desenvolveu programas importantes para a ampliação e utilização das energias renováveis. Destacando programas como: PRODEEM (Programa de Desenvolvimento Energético de Estados e Municípios), PROINFA (Programa de Incentivos às Fontes Alternativas) e o programa Luz para Todos; que unificam seus objetivos para acabar com a exclusão elétrica no país. As regiões de baixa densidade populacional, como a região Amazônica [2],[4], apresentam baixos índices de eletrificação; em razão deste modelo, pois a extensão da rede para atendimento de poucos consumidores é, geralmente, econômica e ambientalmente inviável.

A grande necessidade da energia elétrica, é explicada por [4],[5], ao afirmarem que a sociedade pós-moderna é dependente deste insumo produtivo e social, de tal forma que, o modus vivendi não seria viável sem o fornecimento regular de energia. O objetivo do estudo de identificar e aplicar de comparações de metodologias para sistemas fotovoltaicos isolados é verificar o potencial de irradiação no local onde será estudado, identificando a melhores propostas de tecnologias alternativas que podem ser usadas dependem do potencial local, sua viabilidade econômica e seu mercado consumidor. A energia eólica foi uma outra alternativa energética foi considerada, no entanto para ser tecnicamente aproveitável, seria necessário que sua densidade fosse maior que $500 \mathrm{~W} / \mathrm{m}^{2}$ a uma altura de $50 \mathrm{~m}$, com velocidade mínima do vento de 7 a 8 $\mathrm{m} / \mathrm{s}$ [7],[8],[9].

\section{REVISÃO BIBLIOGRÁFICA}

Os sistemas fotovoltaicos autônomos ou sistemas isolados são utilizados em lugares onde não há redes elétricas convencionais [10],[11]. No Brasil, há muito desses locais não atendidos por malhas do sistema elétrico nos quais, geralmente, utilizam-se geradores movidos a diesel [12].

Apenas a energia gerada pelos painéis fotovoltaicos, através de uma fonte primária, é caracterizada como sistemas fotovoltaicos isolados. Desta forma, faz-se necessário a utilização de um sistema de armazenamento de energia, geralmente um banco de baterias, para garantir o fornecimento de energia durante a noite ou em grandes períodos sem incidência solar [13],[14].

Diferentemente dos painéis solares térmicos, que são empregados para realizar aquecimento ou para produzir eletricidade a partir da energia térmica do Sol, os sistemas fotovoltaicos têm capacidade de captar diretamente a luz solar e produzir corrente elétrica [13]. Essa corrente é coletada e processada por dispositivos controladores e conversores, podendo ser armazenada em baterias [10],[15],[16]

Segundo [10],[17] os sistemas fotovoltaicos isolados podem ser classificados de duas formas: Sistemas em Série
(Figura 1) e Sistemas em Paralelos e os difere pela forma que o sistema de armazenamento é empregado. Na associação em série, o terminal positivo de um módulo é ligado ao terminal negativo de outro. Neste caso a corrente será igual às correntes individuais, mas tensão total será o resultado do somatório das tensões de cada módulo [13].

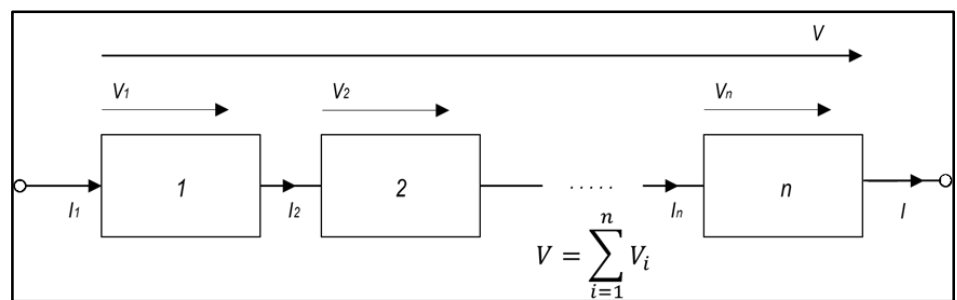

Figura 1. Diagrama de blocos de um sistema fotovoltaico isolado em série.

Fonte: Adaptado Manual de Engenharia para Sistemas Fotovoltaicos [18].

De maneira análoga à conexão das células fotovoltaicas, quando a ligação dos módulos é série, as tensões são somadas e a corrente (para módulos iguais) não é afetada Figura 2, ou seja:

$$
\begin{gathered}
V=V_{1}+V_{2}+\ldots+V_{n} \\
I=I_{1}=I_{2}=\ldots=I_{n}
\end{gathered}
$$

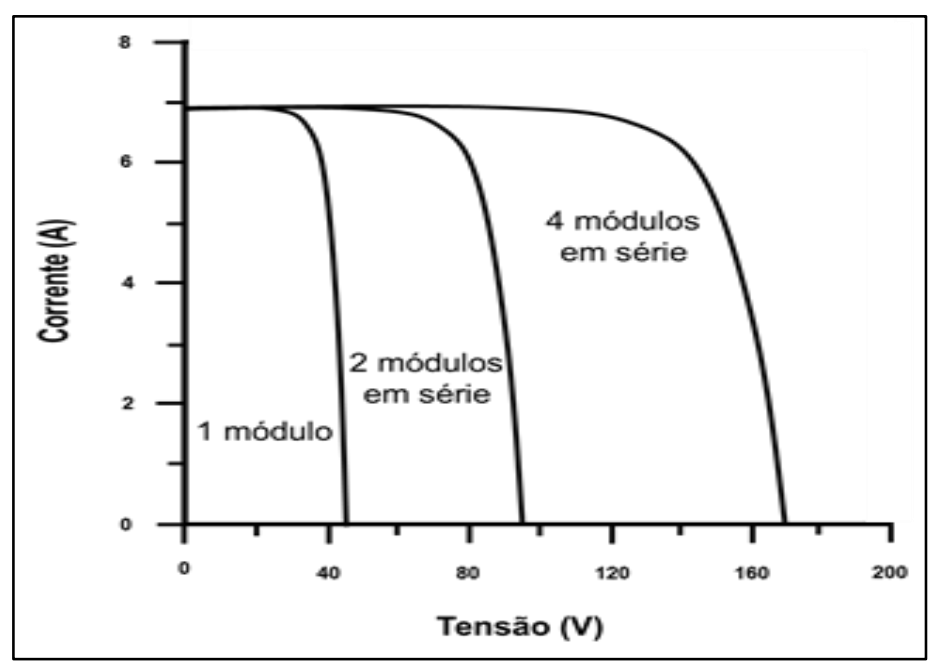

Figura 2. Curvas I-V para um módulo de $220 \mathrm{Wp}, 2$ módulos idênticos associados.

Fonte: Adaptado de [19].

A conexão em paralelo, Figura 3, é feita unindo-se os terminais positivos de todos os módulos entre si e procedendose da mesma forma com os terminais negativos. Esta conexão resulta na soma das correntes sem alteração da tensão, ou seja:

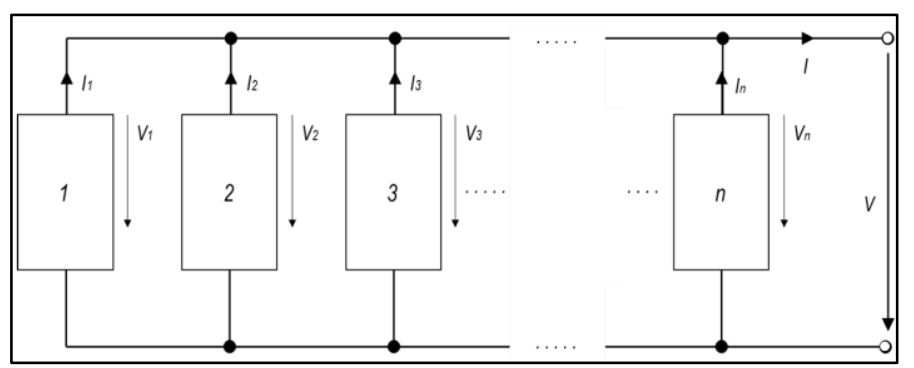

Figura 3. Diagrama de blocos de um sistema fotovoltaico isolado em paralelo.

Fonte: Adaptado de Manual de Engenharia para Sistemas Fotovoltaicos [18]. 


$$
\begin{gathered}
V=V_{1}=V_{2}=\ldots=V_{n} \\
I+I_{1}+I_{2}+\ldots+I_{n}
\end{gathered}
$$

\section{II.1. CIRCUITO EQUIVALENTE DE UMA CÉLULA FOTOVOLTAICA}

Existem pelo menos três abordagens quanto aos circuitos elétricos que representam as células solares [20],[21]; o modelo empírico (ideal), o modelo de um diodo, e o de dois diodos, eles são apresentados na Figura 4.

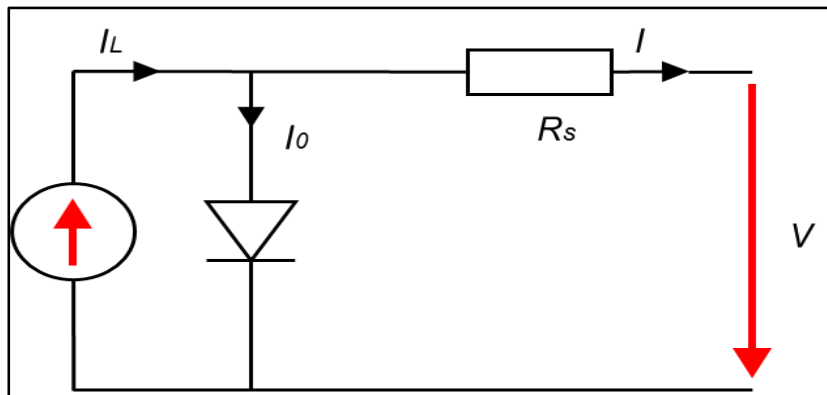

(a)
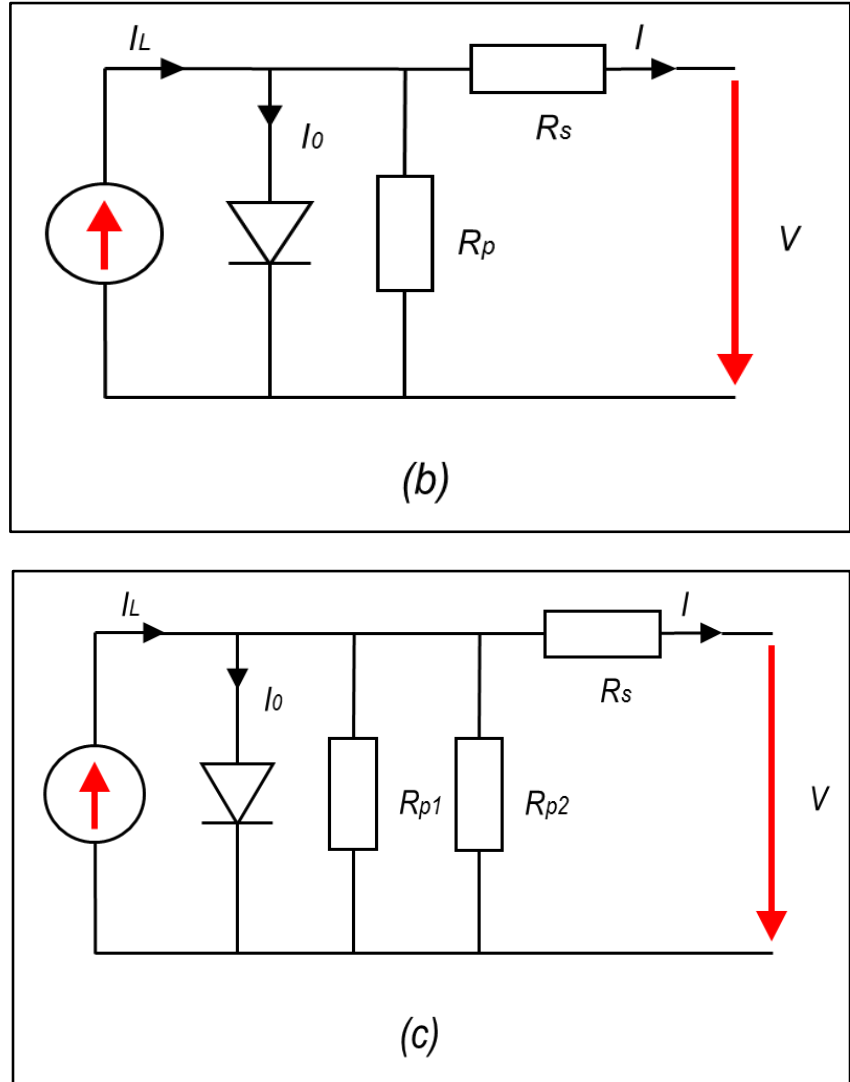

Figura 4 - Circuitos equivalentes de uma célula fotovoltaica: (a) Modelo ideal, (b) Modelo de um diodo, (c) Modelo de dois diodos.

Fonte: Adaptado de Manual de Engenharia para Sistemas Fotovoltaicos [18].

Entre os circuitos elétricos equivalentes da célula solar, o mais aceito, é o de um diodo, também conhecido como modelo real. O circuito equivalente da célula é representado pela Figura 5.

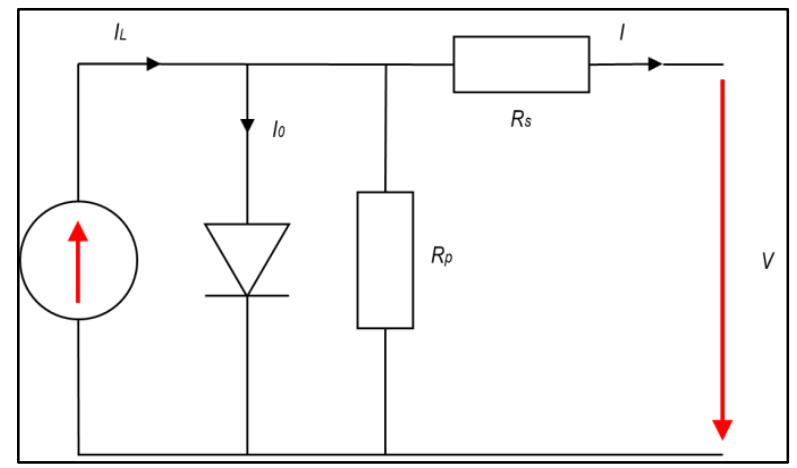

Figura 5 - Circuito equivalente de uma célula fotovoltaica. Modelo real.

Fonte: Adaptado de Manual de Engenharia para Sistemas Fotovoltaicos [18].

A resistência série RS, representa a resistência interna do próprio módulo, que descreve a queda de tensão por meio de perdas ôhmicas (efeito Joule) no material semicondutor, nos contatos metálicos e no contato do metal com o semicondutor. Observa-se que quando as células estão em operação, funcionam como uma fonte de corrente contínua IL e que devido a recombinação de elétrons, parte dessa corrente não é destinada a fotogeração [22],[23].

\section{II.2. PONTO DE MÁXIMA POTÊNCIA (PMP)}

Normalmente, utiliza-se a potência de pico para especificar a potência de sistemas fotovoltaicos. Os principais parâmetros de um sistema podem ser observados na Figura 6: Tensão de circuito aberto VOC, Corrente de curto circuito ISC, Potência máxima PM, Tensão de potência máxima VMP, Corrente de potência máxima IMP [24] [1].

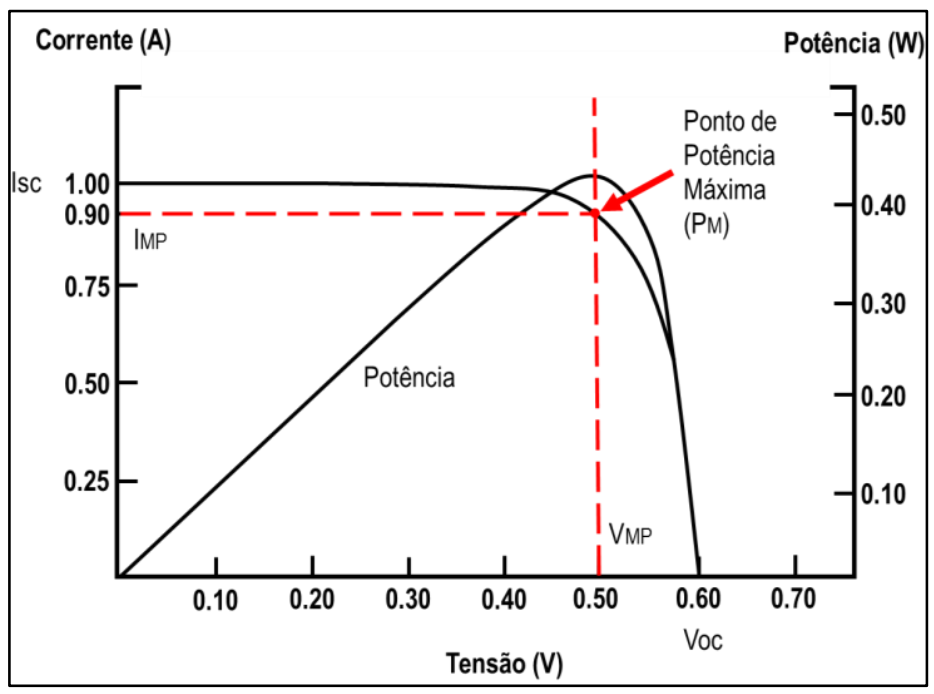

Figura 6 - Curva característica I-V e P-V.

Fonte: Adaptado de [25].

Inicialmente a corrente permanece quase constante até um ponto de máxima potência PM no qual a diminuição exponencial da corrente pesa mais do que o aumento linear da tensão, fazendo que a potência diminua rapidamente, e o módulo passa a comportar-se como uma fonte de tensão [26] [27].

Quando a célula solar está sob a incidência de fótons, a tensão de circuito aberto é aquela medida entre os terminais da célula solar, quando nenhuma corrente circula pela mesma. 
Já a corrente de curto-circuito é aquela que circula quando os terminais da célula solar são curto-circuitados [26].

A Eq. (5) indica a máxima potência que uma célula solar ou um painel fotovoltaico pode fornecer:

$$
P_{M}=V_{M P} I_{M P}
$$

Para melhor desempenho, o aspecto da curva da (Figura 6) deve ser o mais próximo da figura geométrica quadrado. A mensuração deste desempenho pelo Fator de Forma (FF), apresentado pela Eq. (6).

$$
F F=\frac{V_{M P} I_{M P}}{V_{O C} I_{S C}}
$$

O fator de forma (FF), definido como a relação entre a máxima potência do módulo e o produto entre a tensão de circuito aberto (VOC) e a corrente de curto-circuito (ISC), é um fator que diminui com a temperatura [26],[28]. Pode-se analisar os parâmetros de máxima potência da célula é através de seu fator de forma (FF) Eq. (7). Quanto maior o fator de forma, mais próximo de um retângulo a curva será e, consequentemente, maior será a sua área.

A potência máxima varia conforme a corrente e tensão nos terminais do módulo e está dependente das condições ambientais. Para o ponto de máxima potência, a corrente varia com a variação da radiação solar e a tensão varia com a temperatura do módulo [19],[26] Para células de silício mono e policristalino, esse parâmetro varia pouco de uma célula para outra e, conhecendo-se seu valor, pode-se calcular a potência máxima da célula através da seguinte expressão:

$$
P_{M}=F F I_{S C} V_{O C}
$$

\section{II.3.TEMPERATURA DA CÉLULA}

A energia solar que é absorvida pela célula ou pelo módulo é convertida parcialmente em energia térmica e parcialmente em energia elétrica, sendo que a última é removida da célula pelo circuito externo. A energia térmica deve ser dissipada através de combinação de mecanismos de transferência de calor. Segundo [20],[23],[30] baseando no balanço de energia da célula, determina-se a temperatura da célula fotovoltaica Eq. (8).

$$
(\tau \alpha) H_{t, \beta}=\eta_{F V} H_{t, \beta}+U_{L}\left(T_{C}-T_{a}\right)
$$

Onde $\tau$ é a transmitância da cobertura que está sobre a célula, $\alpha$ é a fração da radiação incidente na superfície da célula que é absorvida, $H_{t, \beta}$ é a irradiância global instantânea no plano da célula ou módulo, $\eta_{F V}$ é a eficiência da célula em converter a radiação incidente em energia elétrica.

O coeficiente de perda $U_{L}$ inclui perdas por convecção e radiação da parte superior e inferior da célula fotovoltaica e por condução através da estrutura que contém os módulos, considerando uma temperatura ambiente $T_{a}$ [20],[23],[30].

A máxima eficiência quântica depende do espectro incidente e do band gap, e para um espectro solar padrão é cerca de $33 \%$ para um band gap $(\mathrm{Eg})$ de $1,12 \mathrm{eV}$.

Para um dispositivo real se aproximar do limite de eficiência, ele deve ter um ótimo band gap, forte absorção de fótons, eficiente separação e transporte de portadores de carga, e a resistência de carga deve ser otimizada [1],[18],[25],[26],[27],[31].

\section{II.4.ENERGIA FOTOVOLTAICA}

O aproveitamento da energia solar para produção direta de eletricidade pelo francês Edmond Becquerel que descobriu o efeito fotovoltaico que em um experimento com uma célula eletrolítica, observada pelo efeito, do qual a eletricidade aumentava quando a célula era exposta à luz [18] [32]. Somente em 1954 a primeira célula solar de Silício foi reportada por Chapin, Fuller e Pearson, cuja eficiência de conversão era de 6\% [25],[33],[34].

Segundo [35],[36], ao comprimir (Se) selénio fundido entre as placas feitas a partir de dois metais diferentes, a calcinação foi capaz de preparar filmes finos de (Se) que aderiram a uma das duas placas. Ao pressionar uma folha de ouro (Ag) para a superfície selênio exposta, ele, assim, preparou o primeiro "thin-film" dispositivos fotovoltaicos.

A energia elétrica obtida por fonte solar é resultado da conversão direta da luz solar em eletricidade por meio do efeito fotovoltaico: os sistemas fotovoltaicos captam diretamente a radiação solar, produzindo corrente elétrica.

\section{II.5.RADIAÇÃO SOLAR}

A radiação solar é formada de ondas eletromagnéticas com frequências e comprimentos de ondas diferentes que chegam a Terra por meio do espaço extraterrestre [12],[23]. Frequência e comprimento de onda são grandezas inversamente proporcionais, no entanto, energia e frequência se relacionam de forma direta.

Várias hipóteses foram formuladas, mas nenhuma conseguia explicar de forma satisfatória como o sol era capaz de liberar uma imensa quantidade de energia, durante muito tempo. Hoje, aceita-se a hipótese de provem da fusão de núcleos atômicos.

O processo mais frequente é a transformação de quatro núcleos do isótopo mais comum de hidrogênio $\left(\mathrm{H}^{1}\right)$ em um núcleo do isótopo de hélio $\left(\mathrm{He}^{4}\right)$. A transformação de quatros prótons em uma partícula $\alpha$ de hélio constituída por dois prótons e dois nêutrons [12],[37].

A baixa eficiência de conversão dos dispositivos fotovoltaicos e o alto custo para sua fabricação têm sido objetos de estudo em laboratórios de todo o mundo. $\mathrm{O}$ principal objetivo é tornar a energia solar fotovoltaica competitiva e contribuir com a diversificação da matriz energética. As estratégias para redução do custo consideram junções fotoeletroquímicas, silício policristalino, silício amorfo, nanoestruturas, outros materiais semicondutores e células orgânicas [38],[39].

A radiação provinda do sol que viaja através do espaço é constituída de diferentes comprimentos de onda. A radiação é classificada quanto ao comprimento de onda, e quanto menor esse comprimento, maior a energia de radiação [18],[40]. Nesse sentido, a equação de Planck-Einstein estabelece uma relação entre frequência e energia, de uma onda eletromagnética, através da Eq. (9):

$$
E=h . f
$$

em que E expressa a energia da onda em joules (J) ou elétronsvolt $(\mathrm{eV})$, f a frequência expressa em hertz $(\mathrm{Hz})$ e o $\mathrm{h}$ representa a constante de Planck cujo valor é 6,636 (J.s). Sabe- 
se que a luz é uma onda eletromagnética que se desloca no vácuo do espaço a uma velocidade constante de $300.000 \mathrm{~km} / \mathrm{s}$, aproximadamente, e relaciona-se com a frequência e o comprimento de onda através da equação matemática:

$$
c=\lambda . f
$$

sendo c a velocidade da luz no vácuo, $\lambda$ o comprimento de onda e f a frequência da onda em hertz.

De toda a radiação solar interceptada pela Terra, cerca de $35 \%$ é refletida de volta para o espaço. As nuvens e poeira atmosférica são as maiores responsáveis por essa reflexão da radiação solar, porém, a água, neve e a terra que estão localizadas na superfície terrestre, também provocam uma reflexão dessa radiação [18],[41]. Esta fração que atinge o solo é constituída por uma componente direta (ou de feixe) e por uma componente difusa.

Considerando a radiação solar Figura 7 , que chega à superfície terrestre e incidente sobre uma superfície receptora para geração de energia, tem-se que ela é constituída por uma componente direta (ou de feixe) e por uma componente difusa. A radiação direta é aquela que provêm diretamente da direção do Sol e produz sombras nítidas. A difusa é aquela proveniente de todas as direções e que atinge a superfície após sofrer espalhamento pela atmosfera terrestre.

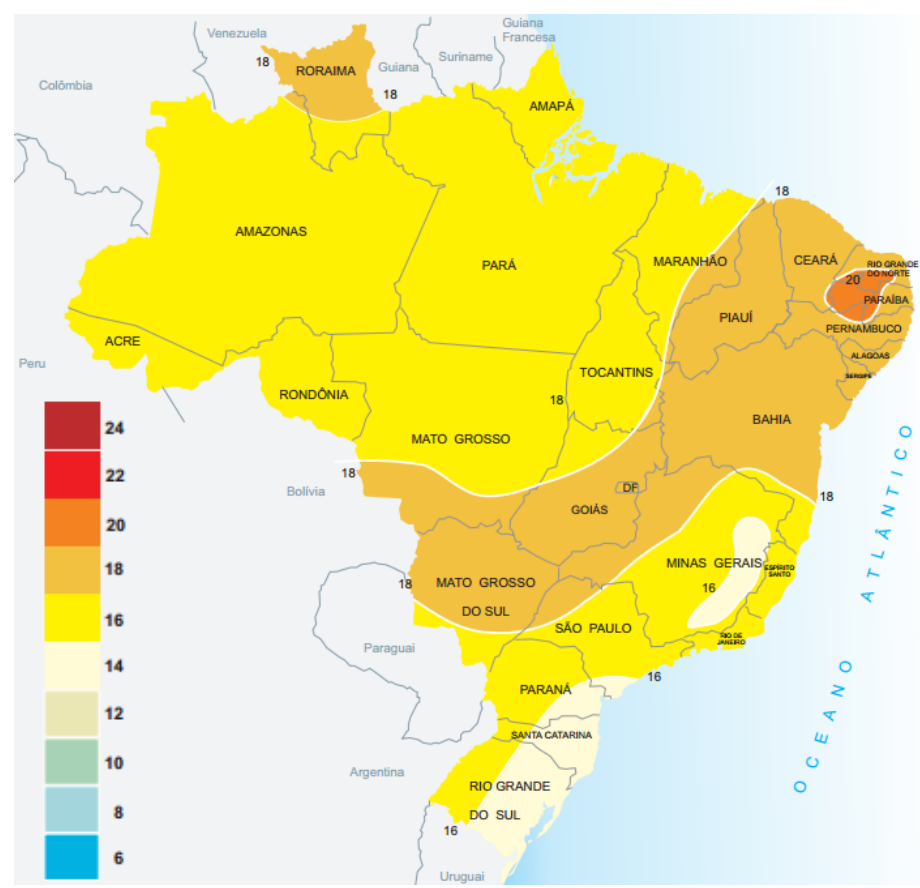

Figura 7 - Radiação solar global diária, média anual (MJ/ $\mathrm{m}^{2}$.dia).

Fonte: Atlas Solarimetrico do Brasil [42].

\section{II.6.IRRADIÂNCIA}

Conhecida por irradiação, é uma grandeza da qual mensura a potência da radiação solar em uma determinada área através da unidade $\mathrm{W} / \mathrm{m}^{2}$ (watts por metro quadrado). Quanto maior a potência de radiação solar, maior a quantidade de energia transportada em um dado instante de tempo. Segundo [12],[43],[44],[45] a medida da irradiância em $\mathrm{W} / \mathrm{m}^{2}$ é muito útil para avaliar a eficiência dos dispositivos e sistemas fotovoltaicos. Com o valor padrão de $1.000 \mathrm{~W} / \mathrm{m}^{2}$, as eficiências das células e módulos fotovoltaicos de diversos fabricantes podem ser especificadas e comparadas, com base numa condição padrão de radiação solar [12],[43],[44].

No topo da atmosfera terrestre o fluxo energético proveniente da irradiância solar varia entre $1325 \mathrm{~W} / \mathrm{m}^{2}$ e 1420 $\mathrm{W} / \mathrm{m}^{2}$. É importante ressaltar a diferenciação de irradiância e irradiação, a irradiância possui unidade de potência por área $\left(\mathrm{W} / \mathrm{m}^{2}\right)$ enquanto a irradiação tem unidade de trabalho por área $\left(\mathrm{Wh} / \mathrm{m}^{2}\right)$ [12],[46].

\section{II.7.PAINÉIS FOTOVOLTAICOS}

Cada célula fotovoltaica isoladamente tem capacidade reduzida de produção de energia elétrica, tipicamente $1,5 \mathrm{~W}$, correspondente a uma tensão de $0,5 \mathrm{~V}$ e uma corrente de $3 \mathrm{~A}$. Portanto, para atender a demanda de energia da maioria dos equipamentos elétricos faz-se necessário a associação de várias células, através de ligações série e/ou paralelo, formando os painéis fotovoltaicos.

O painel fotovoltaico Figura 8, é o responsável por transformar a energia solar em energia elétrica. Ele é formado por células fotovoltaicas conectadas entre si [47],[48].

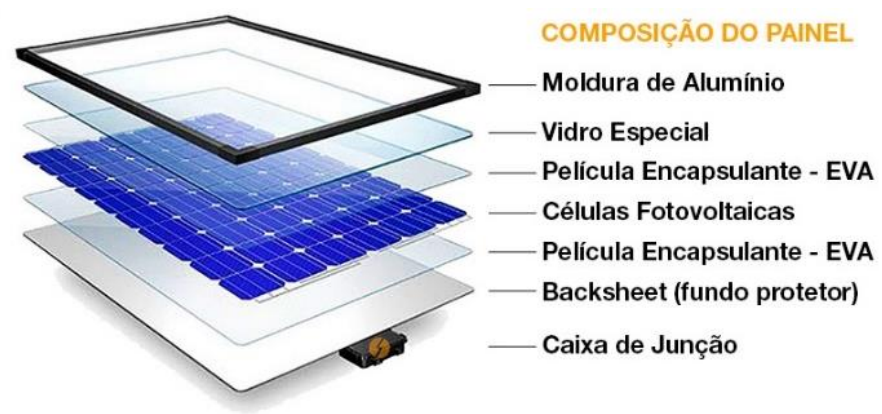

Figura 8 - Composição Básica do Painel Fotovoltaico. Fonte: [49].

Uma propriedade fundamental para as células fotovoltaicas é a possibilidade de fótons, na faixa do visível, com energia suficiente, excitar os elétrons à banda de condução.

Esse efeito, que pode ser observado em semicondutores puros, também chamados de intrínsecos, não garante por si só o funcionamento de células fotovoltaicas. Para obtê-las é necessária uma estrutura apropriada, em que os elétrons excitados possam ser coletados, gerando uma corrente útil. O número de células em um painel é determinado pelas necessidades de tensão e corrente da carga a alimentar. Normalmente um módulo fotovoltaico é constituído por cerca de 33 a 36 células ligadas em série, resultando em tensão suficiente para alimentar uma bateria de $12 \mathrm{~V}$.

As principais tecnologias aplicadas na produção de células e módulos fotovoltaicos são classificadas em três gerações [18]. Os materiais utilizados na fabricação de células solares fotovoltaicas são variados, mas atualmente, cerca de $99 \%$ das células em uso no mundo são constituídas à base de Silício (Si) [32],[36],[50].

A primeira geração é dividida em duas cadeias produtivas: silício monocristalino $(\mathrm{m}-\mathrm{Si})$ e silício policristalino (p-Si), que representam mais de $85 \%$ do mercado, por ser considerada uma tecnologia consolidada e confiável, e por possuir a melhor eficiência comercialmente disponível [26],[36],[34].

A tecnologia que utiliza o silício amorfo (a-Si) também está pronta para o mercado de fotovoltaicos, embora questões como a limitação na eficiência e o efeito de 
degradação da luz incidente devam ser mais discutidos [10],[52],[53].

A eficiência quântica mede a habilidade do material usado em converter fótons em pares elétron-buraco e depende do comprimento de onda usado. Já o rendimento do dispositivo considera os demais parâmetros inerentes à célula fotovoltaica tais como qualidade dos contatos metálicos [27],[54].

\section{II.8.CONTROLADORES DE CARGA}

Sistemas fotovoltaicos destinados a alimentar cargas (equipamentos elétricos) com pouca variação em seu consumo poderiam ser projetadas para operarem sem um controlador de carga, desde que a tensão entregue pelo gerador fotovoltaico seja compatível com a tensão da bateria. Estes são às vezes chamados de sistemas autorregulados (self-regulating systems) [18],[55]. Os controladores são dispositivos eletrônicos operantes em corrente contínua que devem ser utilizados nos sistemas de geração fotovoltaica, evitando sobrecargas ou descargas excessivas da bateria.

Controladores de carga Figura 2.12 são componentes críticos em sistemas fotovoltaicos isolados (SFI), pois, caso venham a falhar, a bateria poderá sofrer danos irreversíveis.

Para garantir o funcionamento dos módulos fotovoltaicos no ponto de máxima potência, mesmo com varrições meteorológicas e variações na carga, a utilização de uma técnica que procure continuamente o ponto de máxima potência deve ser utilizada. Esses algoritmos de controle são conhecidos como MPPT (maximum power point tracking) e podem incrementar a energia produzida ente 15 e $30 \%$ [8],[55],[56],[57].

Os controladores podem diferir basicamente quanto à grandeza utilizada para o controle, forma de desconexão do painel fotovoltaico e estratégia de controle adotada. As grandezas de controle mais utilizadas são: estado de carga (integração do fluxo de corrente na bateria), tensão e densidade do eletrólito da bateria [56].

Configuram-se como funções do controlador de carga: proteção de sobrecarga - o regulador desliga-se da placa solar quando a bateria encontrasse completamente carregada; proteção de descarga excessiva - ao atingir um nível baixo de carga, o consumo de energia é interrompido; gerenciamento da carga da bateria - os controladores mais sofisticados possuem algoritmos de múltiplos estágios para alimentação da bateria [56].

\section{II.10.BATERIAS}

Uma eficiente forma de armazenamento de energia elétrica, as baterias são essenciais para os sistemas off-grid de geração de fontes renováveis. Por isso dá importância de saber as limitações intrínsecas, para que haja correta instalação, prolongando a vida útil e aumentando o grau de confiabilidade. Em sistemas fotovoltaicos isolados da rede elétrica, o uso de dispositivos de armazenamento de energia faz-se necessário para atender a demanda em períodos nos quais a geração é nula ou insuficiente (à noite ou em dias chuvosos ou nublados, com baixos níveis de irradiância solar) [18].

A função prioritária das baterias também chamadas de acumuladores eletroquímicos, num sistema de geração fotovoltaico: é acumular a energia que se produz durante as horas de luminosidade a fim de poder ser utilizada à noite ou durante períodos prolongados de mau tempo [26].

O número de possíveis tipos de baterias é vasto $(\mathrm{Ni}$ $\mathrm{Fe}, \mathrm{Ni}-\mathrm{Zn}, \mathrm{Zn}-\mathrm{Cl}$, etc.) [41]. No entanto, a disponibilidade do mercado reduz a possibilidade de escolha dos tipos a serem empregados. Nos sistemas fotovoltaicos a bateria serve, então, para armazenar a energia produzida e não consumida em períodos de excesso de insolação, para que possa ser posteriormente utilizada em períodos de baixa insolação ou durante a noite, ou seja, garantir o fornecimento constante de energia.

Os fabricantes de baterias podem definir a corrente de carga ou descarga, e as tensões do final de carga ou descarga de seus produtos. Dessa forma, é importante verificar as condições de referência definidas pelos fabricantes quando se compara a capacidade de diferentes produtos.

$\mathrm{O}$ estado de carga de uma bateria, SOC (state of charge), é definido como a relação entre a capacidade da bateria em um estado qualquer e a capacidade nominal desta [18]. SOC possui valores que variam entre 0 e 1 , onde $\mathrm{SOC}=$ 1, significa que a bateria está totalmente carregada enquanto que $\mathrm{SOC}=0$, totalmente descarregada.

Muitas vezes, ao invés de se usar o SOC, a profundidade de descarga, PD (depth of discharge) [41]. A PD é definida como $0 \%$ quando a bateria está totalmente carregada e $100 \%$ quando está totalmente descarregada $(\mathrm{PD}=100 \%$ SOC). Por exemplo, a remoção de 25 (Ah) de uma bateria com capacidade nominal de $100(\mathrm{Ah})$ provoca uma profundidade de descarga de $25 \%$, resultando num estado de carga de $75 \%$.

A relação entre a capacidade nominal da bateria e a corrente em que se realiza a descarga (ou carga), chama-se de regime ou taxa de descarga. Da qual é expressa normalmente em horas. Segundo [41], é representado na forma de sub índice ao lado do símbolo da corrente. $\mathrm{Na}$ grande maioria das aplicações fotovoltaicas, os regimes de carga e descarga oscilam entre I20 e I100, valores relativamente baixos. Isso explica o calor da corrente produzida internamente pelo efeito Joule no interior da bateria, seja pequeno. O que iguala a temperatura interna da bateria com a temperatura ambiente.

A energia nominal (Wh) contida em uma bateria é definida pela tensão nominal da bateria (V) vezes a sua capacidade nominal de corrente (Ah) [18],[55],[58],[59].

Por fim, o rendimento energético de uma bateria a um certo estado de carga é definido como a relação entre a energia (Wh) extraída da bateria durante um processo de descarga e a energia necessária para restabelecer a carga original.

$\mathrm{O}$ banco de baterias, nestes sistemas, acaba se tornando um dos componentes mais caros [55],[58],[59],[60], podendo representar até $15 \%$ dos custos iniciais para a instalação do sistema fotovoltaico, ou até mesmo $46 \%$ [55],[58],[59],[60] se forem considerados os custos de manutenção do sistema. Este aumento nos custos se dá principalmente pelo fato das baterias possuírem vida útil muito inferior aos demais componentes do sistema fotovoltaico.

\section{II.11.INVERSORES}

Dispositivo eletrônico que converte a corrente contínua (C.C) gerada no painel fotovoltaico em corrente alternada (C.A), de forma a permitir a utilização de eletrodomésticos convencionais. Alguns sistemas de pequeno porte não empregam inversor e alimentam as cargas diretamente por corrente contínua (C.C), tais como lâmpadas, TV etc. [61] [12].

Existem três tipos de inversores disponíveis no mercado, os inversores de onda senoidal modificada, os de onda senoidal pura e os inversores de onda quadrada Figura 9.

( 
Menezes Júnior \& Rodríguez, ITEGAM-JETIA. Vol. 03, № 12, pp.36-49. December, 2017.

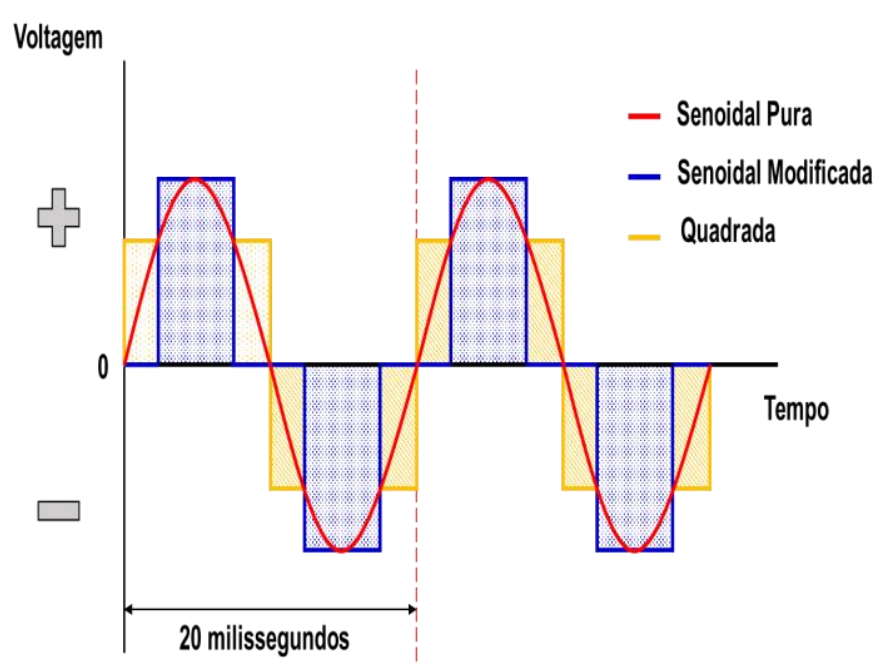

Figura 9 - Tipo de inversores disponíveis. Fonte: Adaptado de [62].

\section{MATERIAIS E MÉTODOS}

O Amazonas possui muitas comunidades que não estão conectadas a rede elétrica convencional. Muitos desses locais apresentam a necessidade de uma fonte de alternativa de geração elétrica como sistemas fotovoltaicos off-grid para o auxílio de diversas atividades como iluminação, irrigação, bombeamento, entre outras. Dentro dessa conjuntura, a utilização de programas de dimensionamento, como o proposto nesse trabalho, estabelece uma base confiável de dados para uma possível implementação do sistema.

A escolha da localidade se deu em função da localização e da potência instalada, buscando representar $\mathrm{o}$ porte $\mathrm{e}$ complexidade de logística. O compromisso com cidade do autor, como referência escolhida para este trabalho fica localizada no estado do Amazonas, no município de Itacoatiara Figura 10 com coordenadas: latitude $03^{\circ} 08^{\prime} 35^{\prime}$ ' S e longitude $58^{\circ} 26^{\prime} 39^{\prime}$ ' O, disponibilizadas pelo IBGE e Tabela 1.

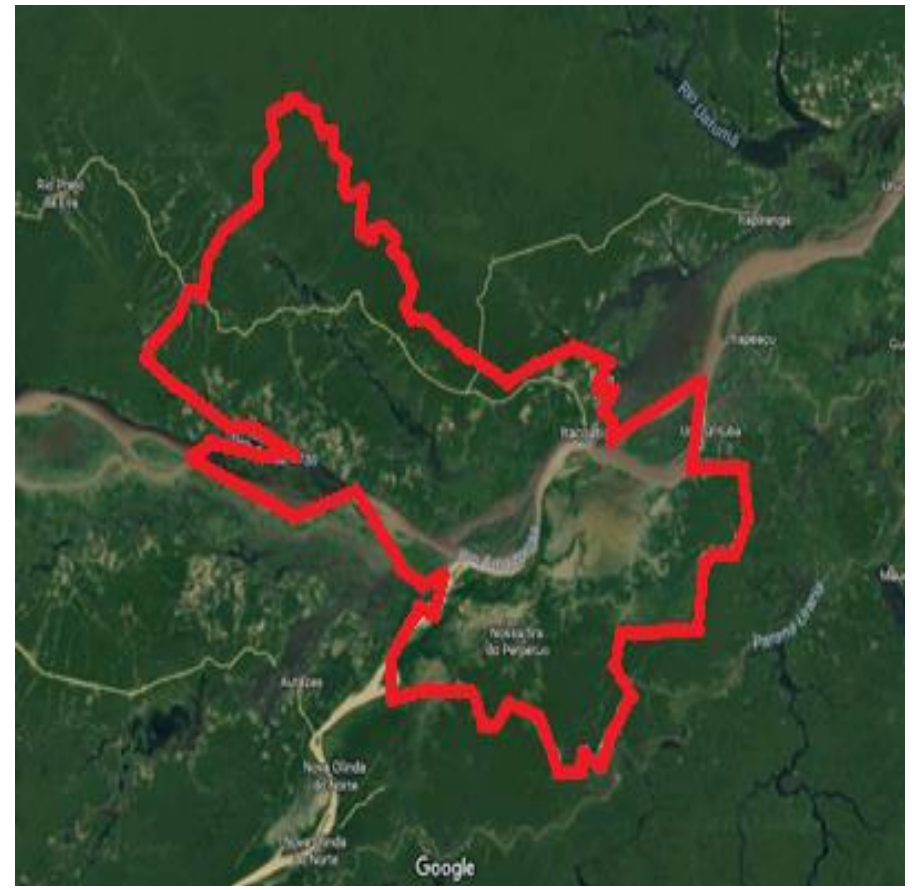

Figura 10 - Localização territorial do município de Itacoatiara - Amazonas.

Fonte: GoogleMaps. Acessado dia 10 de Abril de 2017.
Tabela 1: Dados referentes ao local de estudo.

\begin{tabular}{|c|c|c|c|}
\hline & Un. & $\begin{array}{l}\text { Localização dos } \\
\text { dados climáticos }\end{array}$ & Local das instalações \\
\hline Nome & & $\begin{array}{c}\text { Brasil - AM - } \\
\text { Itacoatiara }\end{array}$ & $\begin{array}{l}\text { Brasil-AM - } \\
\text { Itacoatiara }\end{array}$ \\
\hline Latitude & ${ }^{\circ} \mathrm{N}$ & $-3,1$ & $-3,1$ \\
\hline Longitude & ${ }^{\circ} \mathrm{E}$ & $-58,4$ & $-58,4$ \\
\hline $\begin{array}{c}\text { Zona } \\
\text { Climática }\end{array}$ & - & $\begin{array}{c}\mathrm{A} \\
\text { Muito quente - Úmido }\end{array}$ & $\begin{array}{c}1 \mathrm{~A} \\
\text { Muito quente - Úmido }\end{array}$ \\
\hline Elevação & $\mathrm{m}$ & 40 & 0 \\
\hline
\end{tabular}

Fonte: Adaptado de Software RETScreen Expert - Versão 6.0.7.55.

\section{III.1.AVALIAÇÃO DO POTENCIAL ENERGÉTICO}

É necessário fazer uma avaliação do potencial energético solar, que constitui em buscar a quantidade de radiação solar incidente sobre o painel fotovoltaico de forma que se possa calcular a energia gerada. Os primeiros dados a coletar para o dimensionamento do sistema fotovoltaico são os de incidência solar que podem ser obtidos através do mapa solarimétrico da região na qual se pretende instalar os módulos fotovoltaicos.

\section{III.2.NÍVEIS DE IRRADIAÇÃO DO LOCAL E ARREDORES}

Uma forma bastante conveniente de se expressar o valor acumulado de energia solar ao longo de um dia é através do número de Horas de Sol Pleno (HSP). Esta grandeza reflete o número de horas em que a radiação solar deve permanecer constante e igual a $1 \mathrm{kWh} / \mathrm{m}^{2}$ de forma que a energia resultante seja equivalente à energia acumulada para o dia e local em questão [8]

Para obter-se a irradiação do local é utilizado a ferramenta SunData, fornecida pela CRESESB e disponibilizada em [8]. Delimitando o interesse a ser adotado, o programa fornece os dados de irradiação incidente ao plano inclinado convertidos para seu valor médio diário em $\mathrm{kWh} / \mathrm{m}^{2}$.dia, utilizando o valor numérico HSP.

Desta forma, ao inserirmos no SunData as coordenadas, descritas no item III, é possível obter valores de irradiação solar, $\mathrm{kWh} / \mathrm{m}^{2}$.dia correspondentes às diárias médias mensais para os 12 meses do ano para as cidades pontuadas.

Tabela 2: Dados de radiação diária média mensal em $\mathrm{kWh} / \mathrm{m} 2$ dia das cidades comparadas.

\begin{tabular}{|l|c|c|c|}
\hline & Itacoatiara & Manaus & Parintins \\
\hline Latitude $\left({ }^{\circ} \mathbf{S}\right)$ & 3,1 & 3,1 & 2,6 \\
\hline Longitude $\left({ }^{\circ} \mathbf{O}\right)$ & 58,441666 & 60,025 & 56,735833 \\
\hline Distância $(\mathbf{K m})$ & 4,8 & 175,8 & 199,3 \\
\hline Janeiro & 3,81 & 4,45 & 4,39 \\
\hline Fevereiro & 3,89 & 4,51 & 4,19 \\
\hline Março & 3,75 & 4,52 & 4,47 \\
\hline Abril & 3,78 & 4,50 & 4,28 \\
\hline Maio & 4,14 & 4,44 & 4,44 \\
\hline Junho & 4,17 & 4,73 & 4,56 \\
\hline Julho & 4,89 & 5,12 & 5,31 \\
\hline Agosto & 5,17 & 5,64 & 5,97 \\
\hline Setembro & 4,78 & 5,64 & 5,67 \\
\hline Outubro & 4,39 & 5,48 & 5,81 \\
\hline Novembro & 4,33 & 5,26 & 5,44 \\
\hline Dezembro & 3,97 & 4,79 & 4,94 \\
\hline Média & 4,26 & 4,92 & 4,96 \\
\hline Delta & 1,42 & 1,20 & 1,78 \\
\hline
\end{tabular}

Fonte: Adaptação SunData. Acessado dia 17 de Abril de 2017.

O programa retorna valores para três regiões Tabela 2, incluindo o município de estudo: Itacoatiara (ponto central). Manaus (176,7 Km) e Parintins (197,9 Km). 
Dados mostram que entre os meses de JulhoNovembro há maiores taxas de irradiação em relação à média calculada no período de 12 (doze) meses Figura 11.

Irradiação Solar no Plano Horizontal para Localidades Próximas

$3,125917^{\circ} \mathrm{S} ; 58,435728^{\circ} \mathrm{O}$

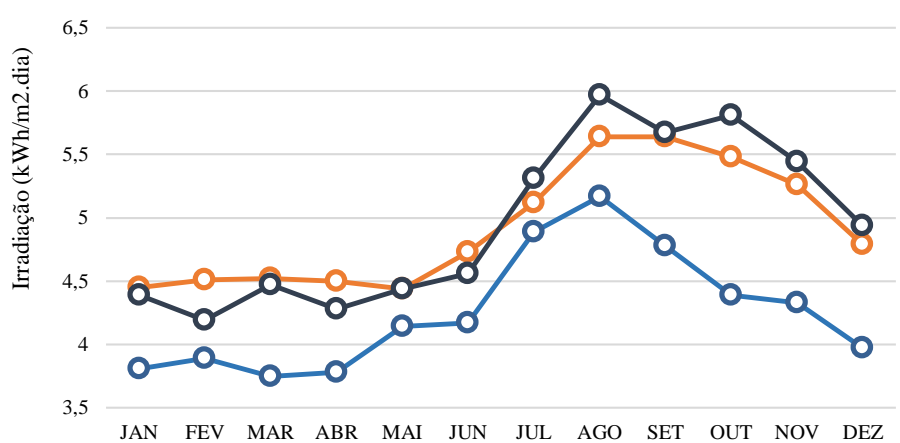

$\longrightarrow$ ITACOATIARA $\longrightarrow$ MANAUS $\longrightarrow$ PARINTINS

Figura 11 - Ponto de localização (1) $03^{\circ} 08^{\prime} 35^{\prime}$ ' S - 58 26' 39" O.

Fonte: SunData. Acessado dia 17 de Abril de 2017.

Apesar dos dados encontrados no município de Itacoatiara estarem abaixo dos demais municípios, é importante ressaltar a grande importância que este trabalho significa para o autor.

Após análises dos dados, os resultados apresentados no capítulo 4 mostram que mesmo com uma média de irradiação anual abaixo das cidades próximas, foi possível realizar todas as etapas do processo de metodologia para plantas fotovoltaicas na região.

O índice solarimétrico da CRESESB é representado pela grandeza $\mathrm{kWh} / \mathrm{m}^{2}$.dia, ou seja será a quantidade de watts que incidem em uma área de 1 metro quadrado durante um dia. Este resultado representa uma estimativa média anual do índice solarimétrico local.

Os valores de irradiação dependentes das inclinações retornados pelo SunData, para o local de estudo considerando a inclinação conforme a latitude local, são apresentados na Tabela 3 e graficamente na Figura 12.

Tabela 3: Dados de radiação diária média mensal em $\mathrm{kWh} / \mathrm{m} 2$ dia por inclinações - Itacoatiara

\begin{tabular}{|l|c|c|c|c|}
\hline & $\begin{array}{c}\text { Plano } \\
\text { Horizontal }\end{array}$ & $\begin{array}{c}\hat{A} \text { ingulo } \\
\text { igual a } \\
\text { latitude }\end{array}$ & $\begin{array}{c}\text { Maior } \\
\text { média } \\
\text { anual }\end{array}$ & $\begin{array}{c}\text { Maior } \\
\text { mínimo } \\
\text { mensal }\end{array}$ \\
\hline Inclinação & $0^{\circ} \mathrm{N}$ & $3^{\circ} \mathrm{N}$ & $6^{\circ} \mathrm{N}$ & $0^{\circ} \mathrm{N}$ \\
\hline Janeiro & 3,81 & 3,75 & 3,69 & 3,81 \\
\hline Fevereiro & 3,89 & 3,86 & 3,82 & 3,89 \\
\hline Março & 3,75 & 3,75 & 3,73 & 3,75 \\
\hline Março & 3,75 & 3,75 & 3,73 & 3,75 \\
\hline Abril & 3,78 & 3,81 & 3,83 & 3,78 \\
\hline Maio & 4,14 & 4,21 & 4,27 & 4,14 \\
\hline Junho & 4,17 & 4,26 & 4,35 & 4,17 \\
\hline Julho & 4,89 & 5,00 & 5,10 & 4,89 \\
\hline Agosto & 5,17 & 5,24 & 5,30 & 5,17 \\
\hline Setembro & 4,78 & 4,79 & 4,80 & 4,78 \\
\hline Outubro & 4,39 & 4,36 & 4,32 & 4,39 \\
\hline Novembro & 4,33 & 4,27 & 4,20 & 4,33 \\
\hline Dezembro & 3,97 & 3,90 & 3,83 & 3,97 \\
\hline Média & 4,26 & 4,27 & 4,27 & 4,26 \\
\hline Delta & 1,42 & 1,50 & 1,61 & 1,42 \\
\hline
\end{tabular}

Fonte: Adaptação SunData. Acessado dia 17 de Abril de 2017.
Irradiação Solar no Plano Incilinado - Itacoatiara, $\mathrm{AM}$ - BR

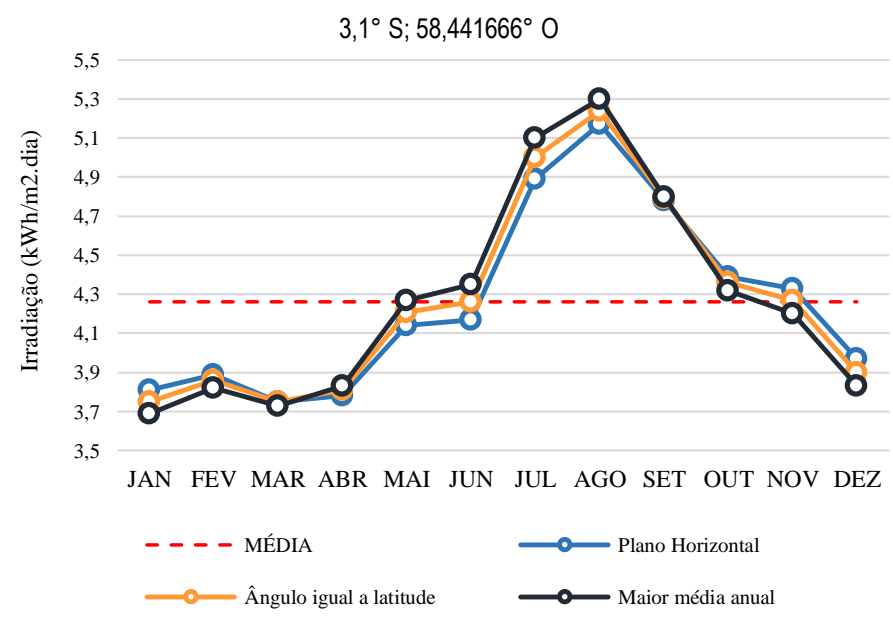

Figura 12 - Ponto de localização [1] $03^{\circ} 08^{\prime} 35^{\prime \prime} \mathrm{S}-58^{\circ} 26^{\prime}$ 39 " O.

Fonte: SunData. Acessado dia 17 de Abril de 2017.

Para projetos Off-Grid, devemos escolher o menor valor apresentado na Tabela 3.2 - Maior mínimo mensal, contido no Anexo IV; que neste caso seria atribuído como índice solar métrico para dimensionamento do projeto o valor de $3,75 \mathrm{kWh} / \mathrm{m} 2$.dia, referente ao mês de março. Com base nesses dados projetados, podemos iniciar as características do projeto isolado dimensionado para uma demanda de $100 \mathrm{~kW}$.

\section{III.3.SOFTWARES}

Os programas de simulação podem ser ferramentas valiosas, permitindo fornecer o melhor planejamento possível do sistema fotovoltaico a projetar conforme demandas do usuário. É importante salientar que em uma simulação se procuram modelos mais exatos e são levadas em conta diferentes situações que na vida real podem ser apresentadas, resultando em processos mais lentos e com grande quantidade de informação, com a qual o usuário geralmente não conta.

Em um dimensionamento procura-se, sem um acompanhamento estrito do fluxo de energia, uma forma rápida e fácil de obter um resultado com uma boa precisão. No caso dos sistemas isolados, esses programas são de grande ajuda, onde as variáveis dependem da natureza das cargas, do nível de segurança desejado ante possíveis falhas no sistema e da quantidade e qualidade das fontes de geração da energia. A maior parte dos programas revisados tem base de dados da irradiância, e em alguns casos, dados da temperatura ambiente também.

\section{III.4.PVSYST}

O software PVSyst - Versão 6.43 foi desenvolvido inicialmente pela Universidade de Genebra (Suíça) e é comercializado atualmente pela companhia PVSyst SA.

O software permite ao usuário trabalhar em diferentes níveis de complexidade, desde um estágio inicial de representação até um detalhado sistema de simulação. Apresenta também uma ferramenta adicionais, tridimensionalmente, que leva em conta as limitações no horizonte e aqueles objetos que possam projetar sombras.

O banco de dados do software permite importar dados dos programas Meteonorm e TMY2, o que facilita comparar 
valores simulados com os valores medidos. Possui um banco de dados extensos e realimentados de acordo com a necessidade do usuário. O programa apresenta as perdas do sistema fotovoltaico e a sua taxa de desempenho; se o usuário adicionar o custo de cada componente à base de dados existentes, o programa pode projetar os custos de produção de energia em adição a uma série de parâmetros técnicos, fornecidos no fim da simulação.

\section{III.5.RETSCREEN EXPERT}

O Renewable Energy Techniques Screen (RETScreen Expert - Versão 6.0.7.55), Figura 3.7 contido no Anexo IX, é direcionado para implementação de projetos de energia renovável e não renovável e eficiência energética, possibilitando redução do custo dos estudos de pré-viabilidade. O programa avalia a produção de energia, os custos durante o tempo de vida e redução na emissão dos gases de efeito estufa.

É utilizado para realização de estudos preliminares. $\mathrm{Na}$ área fotovoltaica, pode determinar, para os três tipos básicos de aplicações (Sistemas conectados à rede, sistemas isolados e bombeamento de água) os custos de produção de energia e redução de gases emitidos. Configuração de sistemas híbridos simples também podem ser avaliadas. Possui base de dados de radiação para mais de 1000 localidades no mundo, assim como dados de irradiância para localidades remotas, através de informações de satélites.

De forma geral, o programa analisa projetos de energia limpa, englobando diversos projetos, incluindo sistemas fotovoltaicos. O software é muito importante para visualizar a viabilidade o projeto, analisando gastos (financeiros de recursos, de pessoa, etc.) e retornos, a fim de evitar possíveis "frustações" quando o projeto for colocado em prática.

\section{III.5.NREL SYSTEM ADVISOR MODEL (SAM)}

O System Advisor Model (SAM), é um modelo de desempenho e econômico. Ele promove a utilização de uma metodologia consistente para análise de todas as tecnologias solares, incluindo o financiamento e os pressupostos de custos.

O objetivo deste projeto é acelerar a tomada de decisões para pessoas associadas a indústrias de energia renovável. A SAM reforça o desenvolvimento das prioridades e direção do programa e também o investimento consecutivo necessário para apoiar as atividades de P\&D solar. É preferível usar o software SAM juntamente com a análise de custos e análise de custos e de penetração de mercado. A gama do software abrange gerentes de projetos e engenheiros, bem como designers de programas de incentivo, desenvolvedores de tecnologia e pesquisadores.

O SAM usa uma tecnologia orientada por sistemas (SDA) e System Energy Technologies Program (SETP). A SDA faz uma ponte sobre os requisitos do mercado com esforços de P\&D. Ele avalia a especificidade das melhorias de P\&D e seu aumento para o custo e desempenho geral do sistema. O SDA é muito útil para alocação eficiente de recursos. A SAM avalia vários tipos de financiamento e uma variedade de modelos de custos específicos de tecnologia para quase todas as tecnologias. As tecnologias SETP atualmente representadas no SAM incluem sistemas de cilindro parabólico concentrador de energia solar e também placas fotovoltaicas e tecnologias de concentração. $\mathrm{O}$ custo total instalado, a soma dos custos diretos e indiretos, é usado para calcular o custo de energia nivelado no SAM.

\section{RESULTADOS E DISCUSSÕES}

Para dimensionamento, leva-se em consideração alguns fatores influentes. O principal deles é o índice de irradiação, que varia de acordo com cada localidade, e é medido em $(\mathrm{kWh} / \mathrm{m} 2$.dia) para $5 \mathrm{~h}$ no dia, que é a média de irradiação plena no Brasil.

Geralmente em projetos de dimensionamentos de sistemas fotovoltaicos, se utiliza o mês crítico na escolha da irradiação que será adotada pelo projeto. Dessa forma, é adotado o pior mês como referência de irradiação, ou seja 3,57 (kWh/m2.dia) [8].

O método do mês critico também é chamado de intuitivo e consiste na realização do dimensionamento do sistema considerando um balanço de energia durante o período do ano no qual ocorrem as condições médias mais desfavoráveis. Supõe-se que se o sistema funcionar adequadamente nesse mês, isso ocorrerá também nos demais meses do ano, assim sendo, o sistema produzirá mais energia nos outros meses nos quais as condições forem mais favoráveis.

A carga fixada em $100 \mathrm{~kW}$, constante ao longo do ano, pode ser dimensionada com base no mês de pior irradiação solar no ano. Este método, como outros simplificados, tem a desvantagem de não otimizar energeticamente a instalação, já que não faz um seguimento contínuo dos parâmetros envolvidos. $\mathrm{O}$ método utiliza valores médios mensais de irradiação solar e da carga, considerando-se somente os valores do mês mais desfavorável na relação carga/irradiação, proporcionando um excesso de energia nos meses mais favoráveis.

\section{IV.1.ANÁLISE PVSYST}

O tamanho do sistema é dependente da configuração de carga. O dimensionamento da matriz fotovoltaica e o arranjo de células solares devem ser feitos bem como as especificações das baterias e do regulador do banco de dados. As baterias fornecem energia em caso de emergências.

O projeto do sistema isolado depende de parâmetros principais como os dados meteorológicos, design do sistema, estudos de sombreamento, determinação das perdas e avaliação econômica. O ângulo azimutal indica a orientação do painel em relação ao Norte, para o local proposto utiliza-se $0^{\circ}$, com inclinação de $6^{\circ}$ afim de obtenção do máximo do sistema.

As classificações das baterias são de $12 \mathrm{~V}$ e um total de 64 baterias em 2 x 32 utiliza-se para o sistema. A classificação do módulo fotovoltaico de configuração: $110 \mathrm{Wp}$ e $19 \mathrm{~V}$ com arranjo consistente de 72 células em 10 x 10 .

$\mathrm{O}$ layout do módulo descreve o efeito do sombreamento em células solares individuais, bem como em todo o sistema. O diagrama de saída de entrada diária exibe a relação entre a energia efetiva na saída da matriz e a energia incidente global no plano do coletor, representa o comportamento do sistema em todos os instantes ao longo do ano. Os resultados encontrados para o sistema fotovoltaico isolado, sob demanda de $100 \mathrm{~kW}$, de uma produção normalizada $3.38 \mathrm{kWh} / \mathrm{kWp} /$ day.

Os parâmetros de saída otimizados sob a forma de irradiação global, energia efetiva global, energia disponível, energia não utilizada, demanda de energia pelo usuário, energia fornecida a carga e fração solar obtida a partir da simulação. Os valores médios de irradiação global (GlobHor) 1770,8 $\mathrm{kWh} / \mathrm{m} 2$, energia efetiva global (GlobEff) de $1719,8 \mathrm{kWh} / \mathrm{m}^{2}$, a energia disponível (E Avail) de $10509 \mathrm{kWh}$, a energia não utilizada (Eunused) de 813,9 kWh, a demanda de energia pelo 
usuário ( $E$ User) $9657,7 \mathrm{kWh}$, a energia fornecida para carregar (E Load) de 9659,4 kWh e a fração solar de 0,983.

A energia não utilizada consiste em 0,29 $\mathrm{kWh} / \mathrm{kW} /$ day, as perdas da rede fotovoltaica de 0,98 $\mathrm{kWh} / \mathrm{kW} /$ day, as perdas do sistema de carregamento das baterias de $0,53 \mathrm{kWh} / \mathrm{kW} /$ day e a energia fornecida ao usuário de $3,38 \mathrm{kWh} / \mathrm{kW} /$ day.

A irradiação global horizontal de $1771 \mathrm{kWh} / \mathrm{m} 2$ e irradiação efetiva encontrada $1720 \mathrm{kWh} / \mathrm{m} 2$. Portanto, a perda de energia de $3,4 \%$ com eficiência de $12,24 \%$. A energia nominal no STC foi $13239 \mathrm{kWh}$. A energia efetiva com valor de $10143 \mathrm{kWh}$ e a energia armazenada de $9695 \mathrm{kWh}$ nas baterias. Demanda final para o usuário variação de $9659 \mathrm{KWh}$. Todos os valores correspondem à temperatura ambiente de $25^{\circ}$ C.

\section{IV.2.ANÁLISE RETSCREEN EXPERT}

A plataforma é direcionada para verificar a viabilidade da implementação de projetos, a eficiência energética, possibilitando redução do custo dos estudos os custos durante o tempo de vida e redução na emissão dos gases de efeito estufa. O objetivo é reduzir custos (tantos financeiros como tempo) associados a identificação e acesso a potenciais projetos energéticos. É selecionado o indicador de referência onde realizará o preposto da viabilização financeira.

Com o software, é possível ter retorno de valores referentes as análises de emissões de gases, relativos a outras fontes de energias comparáveis com o sistema fotovoltaico - já pré-estabelecidos na base de dados do RETScreen Expert que realiza gerenciamento de energia renovável destinado a analisar a viabilidade de projetos de eficiência energética, do uso de geração distribuída através de fontes renováveis de energia e da existência de sistemas de cogeração. O desempenho energético das instalações é realizado ao longo dos meses permitindo uma análise de longo prazo.

O modelo de avaliação de projetos de energias renováveis criado pela RETScreen é um dos mais avançados para dar suporte à tomada de decisão no setor das energias renováveis. Além da análise de emissões, o software retorna os parâmetros financeiros e nos retorna com valores relacionados as análises de risco pelo sistema implantado, com análise de performance, número de combinações e parâmetros de custos iniciais.

\section{IV.3.ANÁLISE NREL System Advisor Model (SAM)}

Dessa forma o software NREL System Advisor Model - Versão 2017.1.17, faz previsões de desempenho e custo de estimativas de energia para projetos de energia conectados à rede com base nos custos de instalação e operação e parâmetros de projeto do sistema que pode ser especificado como entradas para o modelo. O primeiro passo na criação de um arquivo SAM é escolher uma opção de tecnologia e financiamento para seu projeto o que automaticamente preenche as variáveis de entrada com um conjunto de valores padrão para o tipo de projeto.

Os projetos podem ser no lado do cliente do medidor de utilidade, comprar e vender eletricidade a preços de varejo, ou no lado da utilidade do medidor, vendendo eletricidade a um preço negociado através de um contrato de compra de energia conforme demonstrados. SAM inclui várias bibliotecas de dados de desempenho e coeficientes que descrevem as características dos componentes do sistema, como módulos fotovoltaicos e inversores. O software permite dentro de seu extenso banco de dados, selecionar componentes ideais para qualquer tipo de sistema fotovoltaico.

Cada tecnologia de energia renovável no SAM possui um modelo de desempenho correspondente que realiza cálculos específicos da tecnologia. Da mesma forma, cada opção de financiamento na SAM também está associada a um modelo financeiro específico com seu próprio conjunto de insumos e saídas. Os modelos financeiros são tão independentes quanto possível dos modelos de desempenho para permitir a consistência nos cálculos financeiros nas diferentes tecnologias. Cada modelo de desempenho representa uma parte do sistema, e cada modelo financeiro representa a estrutura financeira de um projeto. Os modelos requerem dados de entrada para descrever as características de desempenho dos equipamentos físicos no sistema e os custos do projeto. A interface de usuário da SAM possibilita que pessoas sem experiência desenvolvam modelos de computador para construir um modelo de projeto de energia renovável e para fazer projeções de custo e desempenho com base nos resultados do modelo.

O SAM exibe resultados de simulação em tabelas e gráficos, que vão desde a tabela de métricas que exibe o valor presente líquido do projeto, a produção anual do primeiro ano e outras métricas de valor único, ao fluxo de caixa anual detalhado e aos dados de desempenho horário. Uma ferramenta gráfica incorporada exibe um conjunto de gráficos padrão e permite a criação de gráficos personalizados.

\section{CONCLUSÃO}

Diante do exposto, os softwares utilizados devidamente de acordo com a proposta que cada um pode oferecer para o usuário, a Tabela 4, compara de forma inicial os resultados obtidos de uma forma geral, apresentando o melhor de cada software.

Tabela 4: Comparação dos dados gerais dos softwares.

\begin{tabular}{|c|c|c|c|c|}
\hline Descrição & Un. & SAM & PVSyst & $\begin{array}{c}\text { RETScreen } \\
\text { Expert }\end{array}$ \\
\hline Cidade & - & Itacoatiara & Itacoatiara & Itacoatiara \\
\hline Estado & - & Amazonas & Amazonas & Amazonas \\
\hline Time Zone & GMT & -4 & -4 & -4 \\
\hline Latitude & ${ }^{\circ} \mathrm{N}$ & $-3,11$ & $-3,14$ & $-3,1$ \\
\hline Longitude & ${ }^{\circ} \mathrm{E}$ & $-58,38$ & $-58,44$ & $-58,4$ \\
\hline Altitude & $\mathrm{m}$ & 33 & 23 & 40 \\
\hline Plane Tilt & $\circ$ & 6 & 6 & 6 \\
\hline Azimulth & $\circ$ & 0 & 0 & 0 \\
\hline $\begin{array}{l}\text { Global } \\
\text { Horizontal }\end{array}$ & $\begin{array}{c}\mathrm{kWh} / \mathrm{m}^{2} \\
\text { /day }\end{array}$ & 5,35 & 4,85 & 5,12 \\
\hline $\begin{array}{l}\text { Global } \\
\text { Efficiency }\end{array}$ & $\begin{array}{c}\mathrm{kWh} / \mathrm{m}^{2} \\
/ \text { day }\end{array}$ & 4,51 & 4,71 & 4,82 \\
\hline $\begin{array}{l}\text { Diffuse } \\
\text { Horizontal }\end{array}$ & $\begin{array}{c}\mathrm{kWh} / \mathrm{m}^{2} \\
/ \text { day }\end{array}$ & 2,14 & 3,75 & 4,26 \\
\hline $\begin{array}{l}\text { Average } \\
\text { Temperature }\end{array}$ & ${ }^{\circ} \mathrm{C}$ & 26,8 & 26,4 & 26,6 \\
\hline $\begin{array}{l}\text { Average } \\
\text { wind speed }\end{array}$ & $\mathrm{m} / \mathrm{s}$ & 0,3 & 0,2 & 0 \\
\hline $\begin{array}{l}\text { Software } \\
\text { Objetive }\end{array}$ & - & $\begin{array}{l}\text { Desempenho e } \\
\text { Financeiro }\end{array}$ & $\begin{array}{l}\text { Dimensionament } \\
\text { o e Desempenho }\end{array}$ & $\begin{array}{c}\text { Análise de } \\
\text { Custos/Riscos } \\
\text { e Análise } \\
\text { Ambiental }\end{array}$ \\
\hline Irradiacion & $\mathrm{kWh} / \mathrm{yr}$ & 1254,32 & 1770,8 & - \\
\hline $\begin{array}{l}\text { Array } \\
\text { Temperature }\end{array}$ & ${ }^{\circ} \mathrm{C}$ & 25,95 & 26,11 & - \\
\hline $\begin{array}{l}\text { Annual } \\
\text { Energy (year } \\
\text { 1) }\end{array}$ & $\mathrm{kWh}$ & 6843 & 9659,4 & - \\
\hline $\begin{array}{l}\text { Global on } \\
\text { Collector } \\
\text { plane }\end{array}$ & $\mathrm{kWh} / \mathrm{m}^{2}$ & - & - & - \\
\hline $\begin{array}{l}\text { System } \\
\text { Production }\end{array}$ & $\mathrm{kWh} / \mathrm{yr}$ & - & 10509 & - \\
\hline $\begin{array}{l}\text { Normalized } \\
\text { prod. }\end{array}$ & $\begin{array}{l}\mathrm{kWh} / \mathrm{k} \\
\mathrm{Wp} / \mathrm{yr}\end{array}$ & - & 3,38 & - \\
\hline $\begin{array}{l}\text { System } \\
\text { Losses }\end{array}$ & $\begin{array}{l}\mathrm{kWh} / \mathrm{k} \\
\mathrm{Wp} / \mathrm{yr}\end{array}$ & - & 0,23 & - \\
\hline $\begin{array}{l}\text { Payback } \\
\text { period }\end{array}$ & $\mathrm{yr}$ & 16,4 & 20 & 20 \\
\hline Debit & $\mathrm{R} \$$ & $44.181,68$ & - & $320.000,00$ \\
\hline $\begin{array}{l}\text { Capacity } \\
\text { factor (year } \\
\text { 1) }\end{array}$ & $\%$ & 16,6 & 12,24 & - \\
\hline $\begin{array}{l}\text { GEE } \\
\text { reduction }\end{array}$ & $\mathrm{tCO} 2$ & - & - & 53,1 \\
\hline
\end{tabular}

Fonte: Autores, (2017). 
Com o software PVSyst foi possível ter abrangência no dimensionamento e desempenho dos sistemas fotovoltaicos e do qual depende principalmente da orientação, localização meteorológica e componentes do sistema. O software analisou o desempenho dos sistemas stand alone, juntamente com os efeitos do sombreamento e as perdas que ocorrem durante a operação. As perdas na forma de perdas de fiação, perdas de temperatura e perda de bateria não utilizada contribuíram para $3,4 \%$ de todo o projeto estabelecido. As perdas podem ser minimizadas pelo planejamento e otimização cuidadosa dos componentes do sistema.

Além disso, com o software foi possível a visualização de uma estrutura ideal para a sua utilização de viabilidade e implantação de novos projetos em diversas áreas. Fornece graficamente valores de produção de energia e sua distribuição diária, mensal e anual. O presente estudo apresenta simulação da demanda de energia da região amazônica, com uma eficiência das células de 12,24\% utilizadas em um sistema fotovoltaico, em combinação com latitude e clima, determinando uma produção anual de 9659 KWh além do que é armazenado em baterias. Este resultado pode ser melhorado ampliando-se a área de maior cobertura para instalação dos módulos fotovoltaicos, bem como melhorias das tecnologias aplicadas.

O software mostrou-se bastante adaptável as mudanças de desempenho requeridas durante a fase de projeto, devido ao seu layout de fácil entendimento na elaboração um sistema de qual demanda for necessária.

Já o RETScreen Expert, diferente do PVSyst tem como seu objetivo analisar mais profundamente o desempenho financeiro, payback e riscos durante o projeto de instalação diante das demandas de sustentabilidade e a comparação de eficiências entre diversos tipos de energias renováveis e nãorenováveis. Ao usuário é permitido realizar uma análise em cinco passos, que são descritos no capítulo anterior.

Com um total de custo de investimento inicial de $\mathrm{R} \$ 310.000$, economia dos custos anuais de $\mathrm{R} \$ 4.200$ e economia e receita anual de $\mathrm{R} \$ 11.527$, foi possível ter um retorno positivo e imediato com o VPL de $\mathrm{R} \$ 78.456$, economia de $\mathrm{R} \$ 8.595$ por ano para os próximos 20 anos.

Logo foi possível apresentar resultados positivos na emissão de gases com valor de 4,9 de tCO2 em relação ao caso de referência proposto pelo software de $53,1 \%$. Isso equivale a uma redução de $93 \%$ redução em emissão de gases, com referência em gases $\mathrm{tCO} 2$, com perdas de 7,0\% em relação a eletricidade exportada para o sistema, com fator de emissão de 0,461 tCO2/MWh. Os custo de redução de gases emitidos foram de (-) $\mathrm{RS} / \mathrm{tCO}_{2}$ 162,0.

Com O System Advisor Model (SAM) foi possível identificar com mais facilidade projetos que serão analisados por desempenho e análise financeira facilitando a tomada de decisões para pessoas envolvidas no setor de energia renovável. Retornando valores de energia anual de $6,843 \mathrm{kWh}$ com fator de capacidade do sistema de 1,6\% e payback de 13,6 anos. Logicamente o mais caro de todos devido as escolhas individuais do sistema, comparado com as demais metodologias, torna-se $32 \%$ mais rápido para recuperação econômica.

A utilização dos sistemas integrados nas áreas urbanas ainda é reduzida, porém através do estudo, pôde-se, constatar que a geração solar fotovoltaica representa um papel importante podendo chegar a suprir totalmente as necessidades de várias casas como também auxiliar a concessionária local na redução da sobrecarga nas regiões adjacentes.
Logo, a facilidade de escolhas para projeção de cada item do sistema, torna-se muito interessante para o usuário possa ter comparações e melhores decisões para incluir no sistema. As metodologias apresentaram variações mínimas entres eles e em relação as medidas de irradiação e efetividade que apresenta a região em estudo, com uma eficiência que varia de $(4,51-4,71-4,82) \mathrm{kWh} / \mathrm{m}^{2} / \mathrm{dia}$ dos respectivos softwares.

Este trabalho apresenta os softwares atendem as expectativas para n-tipos de projetos, no entanto, o software que teve uma metodologia que melhor atendeu o autor foi o PVSyst. Devido a sua análise de dimensionamento e desempenho de graus confiantes dos resultados, além de poder estratificar cada passo do devido projeto. Por fim, o potencial da geração elétrica a partir dos sistemas solares fotovoltaicos isolados da rede elétrica demonstrou-se bastante promissor. Grande parte disto, deve-se ao fato dos altos índices de radiação solar no Brasil, das novas tecnologias que implicaram no aumento da eficiência dos módulos de geração.

\section{AGRADECIMENTOS}

Ao PPGEP/UFPA e Instituto de Tecnologia Galileo da Amazônia (ITEGAM), pelo apoio a pesquisa.

\section{REFERÊNCIAS}

[1] Proença, F. P. H., 2007. Tecnologia para Texturização Hemisférica Suave de Células Solares Fotovoltaicas. M.Sc. Universidade Federal de Minas Gerais. Belo Horizonte, MG, Brasil.

[2] Silva, S. B., Severino, M. M., de Oliveira, M. A. G., 2013. A stand-alone hybrid photovoltaic, fuel cell and battery system: A case study of Tocantins, Brazil. Renewable energy, v. 57, pp. 384-389. ISSN 0960-1481.

[3] Ruther, R., 1999. Panorama Atual da Utilização da Energia Solar Fotovoltaica e O Trabalho do Labsolar nesta Área. LABSOLAR - Laboratório de Energia Solar, v. 1, p. 926. Universidade Federal de Santa Catarina - UFSC, Florianópolis/SC.

[4] Pinho, J. T. et al., 2008. Sistemas híbridos - Soluções energéticas para a Amazônia, 1. ed. Brasília, Brasil: Ministério de Minas e Energia, p. 396 p.

[5] Cavalcante, A. S., Queiroz, S., 2012. O desafio da sustentabilidade energética no interior amazônico. In: Anais do II Seminário Internacional de Ciências do Ambiente e Sustentabilidade na Amazônia, Manaus: EDUA, v. 2, pp $412-$ 427, Manaus, Amazonas, Brasil.

[6] Cavalcanti, M. C., Oliveira, K. C., Azevedo, M. S., Neves, A. S., 2008. Comparative study of maximum power point tracking techniques for photovoltaics system. Revista da Associação Brasileira de Eletrônica de Potência-SOBRAEP, v. 13, no. 3, Agosto, pp 141-146.

[7] Belmili, H., Haddadi, M., Bacha, S., Almi, M. F., Bendib, B., 2014. Sizing stand-alone photovoltaic-wind hybrid system: Techno-economic analysis and optimization, In: Renewable and Sustainable Energy Reviews, v. 30, pp. 821832, ISSN http://dx.doi.org/10.1016/j.rser.2013.11.011.
1364-0321, 
[8] CEPEL - CENTRO DE PESQUISAS DE ENERGIA ELÉTRICA, 2013. Atlas do Potencial eólico Brasileiro: Simulações 2013 / CEPEL - Centro de Pesquisas de Energia Elétrica, Rio de Janeiro: CEPEL, 2017, pp 50.

[9] Grubb, M.J. and Meyer, N.I., 1993. Wind Energy: Resources, Systems and Regional Strategies. In: Johansson, T.B., Kelly, H., Reddy, A.K.N. and Williams, R.H., Eds., Renewable Energy: Sources for Fuels and Electricity, Island Press, Washington DC, 157-212.

[10] Lee, M., Soto, D., Modi, V., 2014. Cost versus reliability sizing strategy for isolated photovoltaic micro-grids in the developing world. Renewable Energy, v. 69, pp. p. 16-24. ISSN 0960-1481.

[11] Semaoui, S., Arab, A. H., Bacha, S., Azoui, B., 2013. Optimal sizing of a stand-alone photovoltaic system with energy management in isolated areas. In: Energy Procedia, Volume v. 36, pp. 358-368. ISSN 1876-6102.

[12] Carvalho, C. R. F., 2013. Sistema Fotovoltaivo Isolado: Uma Aplicação Prática no Projeto Xapuri. M.Sc. Universidade Federal de Lavras, Belo Horizonte, MG, Brasil.

[13] Dufo-López, R., Cristóbal-Monreal, I. R., Yusta, J. M, 2016. Stochastic-heuristic methodology for the optimisation of components and control variables of PV-wind-dieselbattery stand-alone systems, In: Renewable Energy, v. 99, pp. 919-935, ISSN 0960-1481, http://dx.doi.org/10.1016/j.renene.2016.07.069.

[14] Dufo-López, R., Lujano-Rojas, J. M., Bernal-Agustín, J. L., 2014. Comparison of different lead-acid battery lifetime prediction models for use in simulation of stand-alone photovoltaic systems. Applied Energy, v. 115, pp. 242-253. ISSN 0306-2619.

[15] Khatib, T., Ibrahim, I. A., Mohamed, A., 2016. A review on sizing methodologies of photovoltaic array and storage battery in a standalone photovoltaic system, In: Energy Conversion and Management, v. 120, pp. 430-448, ISSN 01968904, http://dx.doi.org/10.1016/j.enconman.2016.05.011.

[16] Rezzouk, H., Mellit, A., 2015. Feasibility study and sensitivity analysis of a stand-alone photovoltaic-dieselbattery hybrid energy system in the north of Algeria. Renewable and Sustainable Energy Reviews, Volume v. 43, pp. 1134-1150. ISSN 1364-0321.

[17] Askarzadeh, A., 2017. Distribution generation by photovoltaic and diesel generator systems: Energy management and size optimization by a new approach for a stand-alone application, In: Energy, v. 122, pp. 542-551, ISSN

http://dx.doi.org/10.1016/j.energy.2017.01.105.

0360-5442,

[18] CEPEL - CENTRO DE PESQUISAS DE ENERGIA ELÉTRICA, 2014. Manual de engenharia para sistemas fotovoltaicos. CRECESB - Centro de Referência para Energia Solar e Eólica Sérgio de Salvo Brito, 2014. Disponível em: <http://www.cresesb.cepel.br/publicacoes/download/Manual_d e_Engenharia_FV_2014.pdf>. Acesso em: 17 Abr. 2017.
[19] Seguel, J. I. L., 2009. Projeto de um sistema fotovoltaico autônomo de suprimento de energia usando técnica MPPT e controle digital. M.Sc. Universidade Federal de Minas Gerais, Escola de Enegenharia. Programa de Pós-Graduação em Engenharia Elétrica. Belo Horizonte, MG, Brasil.

[20] Duffie, J. A.; Beckman, W. A., 2013. Solar engineering of thermal processes. John Wiley \& Sons.

[21] Luque, A.; Hegedus, S., 2011. Handbook of photovoltaic science and engineering. 2nd ed. United Kington: John Wiley \& Sons, p. 1162 p.

[22] Ayop, R., Isa, N. M., Tan, C. W., 2017. Components sizing of photovoltaic stand-alone system based on loss of power supply probability, In: Renewable and Sustainable Energy Reviews, ISSN 1364-0321, http://dx.doi.org/10.1016/j.rser.2017.06.079.

[23] bhandari, B. e. a., 2014. A novel off-grid hybrid power system comprised of solar photovoltaic, wind, and hydro energy sources. Applied Energy, v. 133, pp. p. 236-242. ISSN 0306-2619.

[24] Boukenoui, R. e. a., 2016. A new intelligent MPPT method for stand-alone photovoltaic systems operating under fast transient variations of shading patterns. Solar Energy, v. 124, pp. 124-142. ISSN 0038-092X.

[25] Nelson, J., 2003. The Physics of Solar Cells. Imperial College Press, UK.

[26] Pinho, J. T., Galdino, M. A., 2014. Manual de Engenharia para Sistemas Fotovoltaicos. Grupo de Trabalho de Energia Solar-GTES. Rio de Janeiro.

[27] Luque, A.; Hegedus, S., 2011. Handbook of photovoltaic science and engineering. 2nd ed. United Kington: John Wiley \& Sons, p. 1162 p.

[28] Shezan, SK. A., Julais., Kibria, M. A., Ullah, K. R., Saidur, R., Chong, W. T., Akikur, R. K., 2016. Performance analysis of an off-grid wind-PV (photovoltaic)-dieselbattery hybrid energy system feasible for remote areas. In: Journal of Cleaner Production, v. 125, pp. 121-132, ISSN 0959-6526, http://dx.doi.org/10.1016/j.jclepro.2016.03.014.

[29] Bhandari, B. e. a., 2014. A novel off-grid hybrid power system comprised of solar photovoltaic, wind, and hydro energy sources. Applied Energy, v. 133, pp. p. 236-242. ISSN 0306-2619.

[30] Macedo, W. N., 2006. Análise do fator de dimensionamento do inversor (FDI) aplicado a sistemas fotovoltaicos conectados à rede (SFCR). D.Sc - Energia, Universidade de São Paulo, São Paulo, 2006. doi:10.11606/T.86.2006.tde-29112006-153307.

[31] Ibrahim, I. A., Khatib, T., Mohamed, A., 2017. Optimal sizing of a standalone photovoltaic system for remote housing electrification using numerical algorithm and improved system models, In: Energy, v. 126, pp. 392-403, ISSN 0360-5442, http://dx.doi.org/10.1016/j.energy.2017.03.053. 
[32] Rekioua, D., Bensmail, S., Bettar, N., 2014. Development of hybrid photovoltaic-fuel cell system for stand-alone application. In: International Journal of Hydrogen Energy, v. 39, Issue 3, pp. 1604-1611, ISSN 0360-3199, http://dx.doi.org/10.1016/j.ijhydene.2013.03.040.

[33] Torreglosa, J. P. e. a., 2015. Energy dispatching based on predictive controller of an off-grid wind turbine/photovoltaic/hydrogen/battery hybrid system. In: Renewable Energy, v. 74, pp. 326-336. ISSN 0960-1481.

[34] Goetzberger, A., Hebling, C., Schock, H.-W., 2003. Photovoltaic Materials: History, Status and Outlook. Materials Science and Engineering, v. 40, Issue 1, 2003, pp 146. ISSN 0927-796X.

[35] Belmili, H. e. a., 2014. Sizing stand-alone photovoltaicwind hybrid system: Techno-economic analysis and optimization, Renewable and Sustainable Energy Reviews, v. 30, pp. 821-832. ISSN 1364-0321.

[36] Fritts, C. E., 1833. On a New Form of Selenium Photocell. American J. of Science, v. 26, p. 465. Disponível em: <http://www.pveducation.org/node/310>. Acesso em: 17 Abr. 2017.

[37] Jucá, S., Carvalho, P., 2013. Métodos de dimensionamento de sistemas fotovoltaicos: Aplicações em dessalinização. Espaço Cientifico Livre Projetos e editoriais, $1^{a}$ edição. Creative Commons. Duque de Caxias, RJ, Brasil.

[38] Maleki, A., Askarzadeh, A., 2014. Comparative study of artificial intelligence techniques for sizing of a hydrogenbased stand-alone photovoltaic/wind hybrid system. In: International Journal of Hydrogen Energy, v. 39(n. 19), pp. 9973-9984. ISSN 0360-3199.

[39] Granqvist, C. G., 2007. Transparent Conductors as Solar Energy Materials: Panoramic Review. v. 91, ed. 17, 2007, pp. 1529-1598. ISSN 0927-0248.

[40] Rawat, R., Kaushik, S.C., Lamba, R., 2016. A review on modeling, design methodology and size optimization of photovoltaic based water pumping, standalone and grid connected system, In: Renewable and Sustainable Energy Reviews, v. 57, pp. 1506-1519, ISSN 1364-0321, http://dx.doi.org/10.1016/j.rser.2015.12.228.

[41] Jucá, S., Carvalho, P., 2013. Métodos de dimensionamento de sistemas fotovoltaicos: Aplicações em dessalinização. Espaço Cientifico Livre Projetos e editoriais, $1^{a}$ edição. Creative Commons. Duque de Caxias, RJ, Brasil.

[42] CEPEL - CENTRO DE PESQUISAS DE ENERGIA ELÉTRICA, 2000. Atlas Solarimétrico do Brasil : banco de dados solarimetricos. CRECESB - Centro de Referência para Energia Solar e Eólica Sérgio de Salvo Brito, 2000. Disponível em:

<http://www.cresesb.cepel.br/publicacoes/download/Atlas_Sol arimetrico_do_Brasil_2000.pdf $>$. Acesso em: 17 Abr. 2017.

[43] Mamaghani, A. H., Escandon, S. A. A., Najafi, B., Shirazi, A., Rinaldi, F., 2016. Techno-economic feasibility of photovoltaic, wind, diesel and hybrid electrification systems for off-grid rural electrification in Colombia, In: Renewable
Energy, v. 97, pp. 293-305, ISSN 0960-1481, http://dx.doi.org/10.1016/j.renene.2016.05.086.

[44] Muhsen, D. H., Ghazali, A. B., Khatib, T., Abed, I. A., Natsheh, E. M., 2016. Sizing of a standalone photovoltaic water pumping system using a multi-objective evolutionary algorithm, In: Energy, v. 109, pp. 961-973, ISSN 0360-5442, http://dx.doi.org/10.1016/j.energy.2016.05.070.

[45] Rezzouk, H., Mellit, A., 2015. Feasibility study and sensitivity analysis of a stand-alone photovoltaic-dieselbattery hybrid energy system in the north of Algeria. Renewable and Sustainable Energy Reviews, Volume v. 43, pp. 1134-1150. ISSN 1364-0321.

[46] Sandwell, P., Chan, N. L. A., Foster, S., Nagpal, D., Emmott, C. J. M., Candelise, C., Buckle, S. J., Ekins-Daukes, N., Gambhir, A., Nelson, J., 2016. Off-grid solar photovoltaic systems for rural electrification and emissions mitigation in India, In: Solar Energy Materials and Solar Cells, v. 156, pp. 147-156, ISSN 0927-0248, http://dx.doi.org/10.1016/j.solmat.2016.04.030.

[47] PORTAL SOLAR, 2016. Tipos de painel solar fotovoltaico. Disponível em: <http://www.portalsolar.com.br/tipos-de-painel-solarfotovoltaico.html>. Acesso em: 17 Abr. 2017.

[48] Esteves, E. N., 2014. Estudo da viabilidade técnica e econômica para geração de energia elétrica utilizando painel fotovoltaico em uma residência no interior de São Paulo. M.Sc. Universidade Tecnologica Federal do Paraná. Curitiba, PR, Brasil.

[49] NEOSOLAR, 2016. Sistemas de energia solar fotovoltaica e seus componentes. Disponível em: <https://www.neosolar.com.br/aprenda/saiba-mais/sistemasde-energia-solar-fotovoltaica-e-seus-componentes>. Acesso em: 17 Abr. 2017.

[50] Silva, S. B., Severino, M. M., de Oliveira, M. A. G., 2013, A stand-alone hybrid photovoltaic, fuel cell and battery system: A case study of Tocantins, Brazil. Renewable energy, v. 57, pp. 384-389. ISSN 0960-1481.

[51] Branco, J. R., 2003. Desenvolvimento de Insumos para Utilização na Fabricação de Células Solares. In: $2^{\circ}$. Congresso de Inovação em Tecnológica em Energia Elétrica, Anais do $2^{\circ}$.CITENEL, pp. p.534-537, Belo Horizonte, MG, Brasil.

[52] Leite, D. S., 2012, “Degradação Induzida pelo potencial (PID) em módulo fotovoltaico". M.Sc. FEUP - Faculdade de Engenharia da Universidade do Porto. Porto, Portugal.

[53] Rath, J. K., 2003. Low Temperature Polycrystalline Silicon: a Review on Deposition, Physical Properties and Solar Cell Applications. In: Solar Energy Materials \& Solar Cells 76, Volume Netherlands, p. 431-487. ISSN 0927-0248.

[54] Figueiredo, G., Zilles, R., 2016. Degradação induzida pelo potencial em módulos fotovoltaicos, In: Congresso Brasileiro de Energia Solar, Recife, PB, Brasil.

[55] Drir, N., Barazane, L., Loudini, M., 2014. Comparative study of maximum power point tracking methods of 
photovoltaic systems, International Conference on Electrical Sciences and Technologies in Maghreb (CISTEM), Tunis, 2014, pp. 1-5. doi: 10.1109/CISTEM.2014.7077055.

[56] Subudhi; B., Pradhan, R., 2013. A Comparative Study on Maximum Power Point Tracking Techniques for Photovoltaic Power Systems, In: IEEE Transactions on Sustainable Energy, v. 4, no. 1, pp. 89-98, Janeiro 2013. doi: 10.1109/TSTE.2012.2202294.

[57] Villalva, G. M., Gazoli, J. R., 2015. Energia solar fotovoltaica; conceitos e aplicações, $2^{\mathrm{a}}$ Edição. Editora Érica Ltda. São Paulo.

[58] Moraes, G. R., Moehlecke, A., Zanerco, I., Andrade, A. d., 2009. Sistemas fotovoltaicos isolados. In: X Salão de Iniciação Científica - PUCRS, pp. 1142-1144.

[59] Enslin, J. H. R., Wolf, M. S., Snyman, D. B., Swiegers, W., 1997. Integrated Photovoltaic Maximum Power Point Tracking Converter. In: IEEE Transactions on Industrial Electronics, vol. 44, pp. 769 - 773. doi: 10.1109/41.649937.

[60] Martins, D. C., 2000. Conversores Estáticos de Potência Utilizados no Processamento da Energia Solar Fotovoltaica. In: Conferência Internacional de Aplicações Industriais, vol 2, pp. 67-77.

[61] Ma, T., Yang, H., Lu, L., 2013. Performance evaluation of a stand-alone photovoltaic system on an isolated island in Hong Kong. In: Applied Energy, Volume v. 112, pp. p. 663-672. ISSN 0306-2619.

[62] Imhoff, J., 2007, "Desenvolvimento de Conversores Estáticos para Sistemas Fotovoltaicos Autônomos". M.Sc. Universidade Federal de Santa Maria, Santa Maria, SC, Brasil. 